\title{
Effect of Reference Price in PWYTF Pricing in Tourism Sector
}

\author{
Atanu Adhikari \\ Indian Institute of Management Kozhikode, Kozhikode, India \\ Email: atanu.adhikari@iimk.ac.in
}

How to cite this paper: Adhikari, A (2019) Effect of Reference Price in PWYTF Pricing in Tourism Sector. Theoretical Economics Letters, 9, 555-562.

https://doi.org/10.4236/tel.2019.94038

Received: February 5, 2019

Accepted: March 15, 2019

Published: March 18, 2019

Copyright $\odot 2019$ by author(s) and Scientific Research Publishing Inc. This work is licensed under the Creative Commons Attribution International License (CC BY 4.0).

http://creativecommons.org/licenses/by/4.0/

\section{c) (i) Open Access}

\begin{abstract}
While conventional pricing strategy involves sellers to decide price of a tourism product, tourism companies carry the risk of capacity underutilization in many occasions when fixed costs are already incurred. Pay What You Think Fair (PWYTF) pricing mechanism motivates tourists to pay a fair price for unutilized capacity, thereby, increasing sales and profit for marketers. This study shows that PWYTF pricing mechanism with a concrete reference price of customer can generate significantly higher revenue and profit for a long period of time. We have conducted three experiments to show that PWYTF pricing strategy is a profitable and sustainable pricing solution for tourism companies to increase revenue during off-season as well as underutilization of hired capacity. This study opens a new avenue in pricing methods used in tourism industry and contributes in significant way both in academic and practice.
\end{abstract}

\section{Keywords}

Pay What You Think Fair, Willingness to Buy, Willingness to Pay,

Participative Pricing, Reference Price, PWYTF Pricing

\section{Effect of Reference Price in PWYTF Pricing in Tourism Sector}

Pricing is known to be a very important task for tourism companies [1]. Since pricing is the only source of income for the services tourism companies deliver, the obligation for working management is to set the price such a way that it recovers cost and provides sufficient revenue and profit. However, it is extremely difficult to find a mechanism that will give optimum revenue to these companies [2] [3]. A price which is set high has the risk of customer defection, while a lower price reduces revenue. Tourism companies spend a disproportionate amount 
of time determining "how much to charge" and "how to charge" [4]. The problem is further accentuated for tourism services where fixed costs are very high and the variable cost is marginal. It is important to ask the question that is a traditional pricing policy always worked to get higher revenue? How the traditional pricing policy addressed the issue of facility un-utilization? For example, how to recover at least some part of the cost already incurred by the tourism company on the transport they have to hire for under capacity facility subscription; or how to generate revenue of the vacant seats of a yacht that had to be booked for handful tourists? This paper proposes a participative pricing mechanism to address these issues, and to show a new route to the academics and practitioners in tourism research as to how significant revenue can be generated. In this pricing mechanism, tourists are involved in setting up the price for a service.

Tourism research has studied the role of customers in developing new services, improving the product design and advertising the tourism service [5]. This co-creation of product and communication is a well established business activity adopted by tourism companies. In line with the scope creation, this paper advocates that involving customers to set their own price could be beneficial for the tourism companies. Depending upon cost structure and demand of products or services, involving customers to participate in pricing mechanism could be sustainable and highly revenue generating.

Participative pricing is a recent research interest and has gained a reasonable popularity by way of Knowing Your Own Price [6] and Pay What You Want Pricing (PWYW) [7]. In Pay What You Want Pricing method, consumers are free to determine the price of the product (including zero price) and pay accordingly. While the neoclassical economic theory suggests that income constrained consumers maximize utility during a transaction with cost constrained firms [8] and recommends that a rational consumer would like to pay zero price for the product she buys, studies have revealed that a successful implementation of the Pay What You Want pricing strategy has generated significant positive revenue [7] [9] [10]. Such delegation of power to the consumer in the matter of deciding the price, combined with their social status, encourages them to pay a reasonable price for the product they buy. There is evidence from practitioners that PWYW pricing strategy has been implemented successfully in restaurants such as Potager in the US or the Der Wiener Deewan of Pakistan based in Vienna or the bars in Berlin. For that matter, a restaurant in India called Seva Café has also started following this technique.

Since the concept of PWYW pricing involves buyers in the pricing process, previous researchers [9] opined that consumers may gradually pay less as they become fully aware of the mechanism of PWYW pricing. In Pay What You Think Fair (PWYTF), we argue that fairness judgment of consumers when asked to pay what they think fair which would reveal the fairness of the price they choose to pay which in turn would fetch higher sales and revenue for sellers for the goods and services that go unsold through regular pricing strategy. PWYTF pricing borrows from the fact that consumer exhibits fairness repeatedly when 
they are asked to decide what price they want to pay.

Consumers' perceptions about price fairness and their behaviour have been studied primarily from the perspectives of utility theory and distributive justice [11] [12] [13], which proposes the effect of equality of outcomes between buyers and sellers [14]. In other words, buyers use their internal reference price or external standards to arrive at a conclusion about what price is fair [15] [16]. In Pay What You Think Fair (PWYTF) pricing we study fairness of the buyer in a transaction. We argue that buyers form a notion about a fair price of the product on the basis of their reference price [17] [18]. Such price evaluation, which is based on the fairness assessment of the product, is motivated by comparative judgment with price of other products in similar outlets [19] and cost of the product to the seller. We argue that according to the theory of justice, buyers would be motivated to pay a price that reduces the difference between the price he pays and his compared price in a reference transaction. Hence, we formulate hypotheses,

$\mathrm{H1}$ : Willingness of consumption of tourism services will significantly increase in case of PWYTF pricing mechanism than a fixed pricing mechanism.

H2: Under PWYTF pricing mechanism, customers will pay a fair price which is significantly higher than the cost of the product when they have a confirmed reference price of the product in offer.

H3: Under PWYTF pricing mechanism, customers may not pay a price which is significantly higher than the cost of the product when they do not have a confirmed reference price of the product in offer.

\section{Empirical Studies}

We conducted three experimental studies in a business school in South India to test these three hypotheses. It is well established procedure to test theory with student sample. Researchers publishing in leading academic journals of consumer research have used student sample in testing hypotheses [20]. Products were selected through a pretest for the experiment. Three categories of services were selected from a pre-test. These were boating in lake in a tourist spot (P1), food items at a fast food corner (P2), and writing pen (P3). Selection of products P2 and P3 took into consideration the fact that consumers have very little information about the cost of the product P3, while they have adequate information about the cost of the food items under sale (i.e. P2).

\subsection{Experiment 1}

To test $\mathrm{H} 1$, we conducted a randomized between-subject experimental study among two groups of students of size 60 each. The students were assigned in two groups randomly. Two groups were places in two classrooms in separate blocks of the school. Students in each of the two groups had similar demographic and socio-graphic profile. Both groups were shown placard of boating in the lake. One group were told the price of one hour boating ride in the lake as Rs. 200 
(\$3.5) per seat while the other group was told that they can pay what they think fair (PWYTF). Willingness to purchase the boat ride were measured in seven point Likert scale, 1 being "will definitely not buy" to 7 being "will definitely buy". Alongwith the willingness to buy of both the groups, their demographic profile were also measured in the questionnaire. We emphasized to the students that it was extremely important for them to imagine themselves as the buyer in the scenario. Participants were asked to try to imagine how they would really feel in these situations [21].

\subsection{Analysis and Result}

Univariate analysis of mean difference of the willingness to buy in two types of pricing mechanism was conducted. We compared the demographic and psychographic profile of the respondents of both groups to assess non-response bias following the reasoning that respondents over the experiment period may be prone to non-response and any difference between them is likely to be symptomatic of non-response bias [22]. We performed t-tests on the responses and found no significant differences between these respondents participated in both groups on any of the demographic and psychographic variables $(p>0.1)$. It is therefore concluded that non-response bias was not a problem with this research. The percentage of male respondents was $54 \%$ and average household income was 674,640. It is found that mean willingness to buy at a fixed price (3.48) was significantly less than the mean willingness to buy at Pay What You Think Fair pricing mechanism $(5.67, \mathrm{~F}(1,118)=62.42, \mathrm{p}<0.001)$.

\subsection{Discussion}

The results support hypotheses H1. It is evident from the result that in the Pay What You Think Fair pricing context, buyers' willingness to buy is significantly more than fixed price context. The result shows the congruence between price participation in the context of PWYTF and individual's perception about higher consumption. We can see here that buyers in the PWYTF environment do not behave as completely rational buyer, and pay a positive price though the buyer is allowed to pay zero amount if they think it fair.

\subsection{Experiment 2}

To test hypotheses $\mathrm{H} 2$, we conducted the second experiment at a South Indian university canteen which is open to both students and faculty members. We conducted the experiment with help of graduate students with incentive through graded project. Since the product had less variable cost compared to fixed cost, it was suitable for participative pricing [7]. A campaign was put up in the campus about the offer of PWYTF two days before the experiment started.

The experiment was conducted where the seller sold food items at a designated place in the campus. There was campaign about the offer of PWYTF before the experiment started. The food items were not regularly sold in the canteen, however, were made of common ingredients. Hence, buyers had a concrete ref- 
erence price of the products under offer. Buyers were then asked to pay what they think fair.

We derived the cost and proposed selling price for the food items in the experiment. We requested three professional food sellers to decide the cost and price of each food items using the same method that they use in other food items they sell. We then took average of these costs and prices proposed by three sellers to decide on the cost and the proposed selling price of each item. The selling price proposed of the food item sold on the day of experiment was 60 and the cost was 35.

To test hypothesis $\mathrm{H} 2$, we conducted univariate analysis of mean difference between the cost of the food items and amount paid by the buyers. We found that the amount paid under PWYTF pricing condition (mean $=42$ ) is significantly higher than the cost of the food item (mean $=35, F(1,228)=33.91, \mathrm{p}<$ 0.001).

\subsection{Discussion}

The results support H2. This shows that tourists would be motivated to pay significantly higher price for the service they buy under PWYTF pricing context. We see here that if consumers have explicit reference price of items under sale, they get a salient link between the value of the offered item and the vendor's monetary investment. Hence, the buyers derive a higher price as fair price when the have an idea about seller's cost to produce the item.

\subsection{Experiment 3}

To test hypotheses $\mathrm{H} 3$, we conducted third experiment at the same business school. Sixty students were selected for the study through a random process. We conducted the experiment with help of graduate students with incentive through graded project.

The experiment was conducted where steel body writing pens were under sale. The sample pens were kept on the table for thorough inspection of the participants. The students were asked to think it a real buying situation and were told that such consideration will make the research successful. Participating students were also told that they should assume that they have surplus money with them to buy the article in display, however, with that money they can also buy other articles which are of similar interest to them. Rook and Fisher [21] suggested that responses that require personal, sensitive nature of purchasing is better performed in an imagined scenario approach since it can reduce the likelihood of social desirability bias [23]. This will also reduce interactive testing effects and increase external validity. We also emphasized to the participants that it was extremely important for them to imagine themselves as the buyer in the scenario. Participants were asked to try to imagine how they would really feel in these situations.

We derived the average cost to retailers of the pen item in the experiment from three retailers same way as we did in experiment 2 . The cost of the pen de- 
rived through this method was $₫ 60$. The average selling price of the pen was 100 . Willingness to pay for the pen was measured through a questionnaire. Alongwith the willingness to pay, the demographic profile of the respondents were also measured in the questionnaire.

To test hypothesis $\mathrm{H} 3$, we conducted univariate analysis of mean difference between the cost of the pen under experiment and amount paid by the buyers. We found that the amount paid under PWYTF pricing condition (mean = $37.67)$ is significantly lower than the cost of the pen $($ mean $=60, \mathrm{~F}(1,118)=$ $148.71, \mathrm{p}<0.001)$.

\subsection{Discussion}

The results support H3. This shows that tourists would not pay enough to cover the cost of the item under sale through PWYTF pricing mechanism when they don't have a confirmed reference price through which they can derive the cost of the product. We see here that when buyers do not have an explicit reference price of items under sale, they are respond to such pricing mechanism to their own favor which may lead to seller's loss. Hence, the buyers derive a low price as fair price when they don't have an idea about seller's cost to produce the item.

\section{General Discussion and Conclusions}

The above three studies show the evidence of a newly proposed participative pricing mechanism, Pay What You Think Fair pricing, using consumers' fairness perception. We have shown that how willingness to pay under PWYTF can help tourism companies to earn higher revenue for unsold services where fixed cost is already incurred. This may help tourism companies to increase cumulative sales, revenue and profit. Our studies found that PWYTF pricing mechanism can significantly influence consumers purchase behaviour. Marketers are to consider that while consumers feel happy to be a part of the pricing of the product they buy, they are also conscious about their self image and pay significantly higher than zero, the best option for a rational consumer.

We showed that since buyers are explicitly asked to behave fairly, the possibility of them paying less than the cost of the product reduces. In many cases where fixed costs are already incurred by tourism companies (e.g. cruise, day tour package, multiplex, theme park etc.) PWYTF pricing strategy may be highly sustainable and can generate significantly higher revenue for the tourism companies than fixed pricing mechanism. We also found that social pressure can increase fairness perception of buyers and consequently may increase their willingness to pay for the product they buy through PWYTF pricing.

\section{Limitations and Future Research}

One limitation is that the study was conducted only in laboratory condition and same can be more generalized with field study. A larger sample would have provided more reliability of the findings as well. Rgarding the scope of future re- 
search, this study provides a novel perspective of reference pricing and several aspects of reference pricing can be investigated in the context of PWYTF pricing. For example, several studies can be conducted to see the effect of framing, cost of products etc on PWYTF pricing context.

\section{Conflicts of Interest}

The author declares no conflicts of interest regarding the publication of this paper.

\section{References}

[1] Guo, X., Ling, L., Dong, Y. and Liang, L. (2013) Cooperation Contract in Tourism Supply Chains: The Optimal Pricing Strategy of Hotels for Cooperative Third Party Strategic Websites. Annals of Tourism Research, 41, 20-41. https://doi.org/10.1016/j.annals.2012.11.009

[2] Clarke, H.R. and Ng, Y.K. (1993) Tourism, Economic Welfare and Efficient Pricing. Annals of Tourism Research, 20, 613-632. https://doi.org/10.1016/0160-7383(93)90087-J

[3] Adhikari, A., Basu, A. and Raj, S.P. (2013) Pricing of Experience Products under Consumer Heterogeneity. International Journal of Hospitality Management, 33, 6-18. https://doi.org/10.1016/j.ijhm.2013.01.002

[4] Keane, M.J. (1997) Quality and Pricing in Tourism Destinations. Annals of Tourism Research, 24, 117-130. https://doi.org/10.1016/S0160-7383(96)00034-5

[5] Adhikari, A. and Bhattacharya, S. (2015) Appraisal of Literature on Customer Experience in Tourism Sector: Review and Framework. Current Issues in Tourism, 1-26.

[6] Spann, M. and Tellis, G. (2006) Does Internet Promote Better Consumer Decisions: A Case of Name Your Own Price Auctions. Journal of Marketing, 70, 65-78. https://doi.org/10.1509/jmkg.70.1.065.qxd

[7] Kim, J.-Y., Natter, M. and Spann, M. (2009) Pay What You Want: A New Participative Pricing Mechanism. Journal of Marketing, 73, 44-58. https://doi.org/10.1509/jmkg.73.1.044

[8] Neumann, V.J. and Morgenstern, O. (1944) The Theory of Games and Economic Behavior. Princeton University Press.

[9] Gneezy, A., Gneezy, U., Nelson, L.D. and Brown, A. (2010) Shared Social Responsibility: A Field Experiment in Pay-What-You-Want Pricing and Charitable Giving. Science, 329, 325-327. https://doi.org/10.1126/science.1186744

[10] Chandran, S. and Morwitz, V.G. (2005) Effects of Participative Pricing on Consumers' Cognitions and Actions: A Goal Theoretic Perspective. Journal of Consumer Research, 32, 249-259. https://doi.org/10.1086/432234

[11] Varian, H.R. (1976) Two Problems in the Theory of Fairness. Journal of Public Economics, 5, 249-260. https://doi.org/10.1016/0047-2727(76)90018-9

[12] Rawls, J. (1999) A Theory of Justice. Belknap Press.

[13] Sharifi-Tehrani, M., Verbič, M. and Chung, J.Y. (2013) An Analysis of Adopting Dual Pricing for Museums: The Case of the National Museum of IRAN. Annals of Tourism Research, 43, 58-80. https://doi.org/10.1016/j.annals.2013.04.001

[14] Xia, L., Monroe, K.B. and Cox, J.L. (2004) The Price Is Unfair! A Conceptual Framework of Price Fairness Perceptions. Journal of Marketing, 68, 1-15. https://doi.org/10.1509/jmkg.68.4.1.42733 
[15] Bolton, L.E., Warlop, L. and Alba, J.W. (2003) Consumer Perceptions of Price (Un) Fairness. Journal of Consumer Research, 29, 474-491. https://doi.org/10.1086/346244

[16] Adhikari, A. and Rao, A.K. (2013) Individual Preference and Bargaining Behavior in Families' Buying Decisions of Restaurant Service. Cornell Hospitality Quarterly, 54, 248-261. https://doi.org/10.1177/1938965512459801

[17] Braun, B.M., Soskin, M.D. and Cernicky, M. (1992) Central Florida Theme Park Pricing: Following the Mouse. Annals of Tourism Research, 19, 131-136. https://doi.org/10.1016/0160-7383(92)90114-5

[18] Adhikari, A. (2014) Differentiating Subjective and Objective Attributes of Experience Products to Estimate Willingness to Pay Price Premium. Journal of Travel Research, 54, 634-644.

[19] Coenders, G., Espinet, J. and Saez, M. (2003) Predicting Random Level and Seasonality of Hotel Prices: A Latent Growth Curve Approach. Tourism Analysis, 8, 15-31. https://doi.org/10.3727/108354203108750148

[20] Peterson, R.A. (2001) On the Use of College Students in Social Science Research: Insights from a Second-Order Meta-Analysis. Journal of Consumer Research, 28, 450-461. https://doi.org/10.1086/323732

[21] Rook, D.W. and Fisher, R.J. (1995) Normative Influences on Impulsive Buying Behavior. Journal of Consumer Research, 22, 305-313. https://doi.org/10.1086/209452

[22] Armstrong, J.S. and Overton, T.S. (1977) Estimating Nonresponse Bias in Mail Surveys. Journal of Marketing Research, 14, 396-402. https://doi.org/10.1177/002224377701400320

[23] Beatty, S.E. and Ferrell, M.E. (1998) Impulse Buying: Modeling Its Precursors. Journal of Retailing, 74, 169-191. https://doi.org/10.1016/S0022-4359(99)80092-X 